\title{
THE INFLUENCE OF LASER PROCESSING ON MICROSTRUCTURE AND SELECTED PROPERTIES OF THE DIFFUSION BORONIZED LAYERS PRODUCED ON TOOL STEEL FOR METAL FORMING
}

\author{
${ }^{1}$ Aneta BARTKOWSKA, ${ }^{2}$ Peter JURČI, ${ }^{2}$ Mária HUDÁKOVÁ, ${ }^{3}$ Dariusz BARTKOWSKI, \\ ${ }^{3}$ Damian PRZESTACKI, ${ }^{2}$ Martin KUSÝ, ${ }^{4}$ Martin KUŘíK \\ ${ }^{1}$ Poznan University of Technology, Faculty of Materials Engineering and Technical Physics, Poznan, \\ Poland, EU, aneta.bartkowska@put.poznan.pl \\ ${ }^{2}$ Slovak University of Technology in Bratislava, Faculty of Materials Science and Technology in Trnava, \\ Trnava Slovakia,EU, p.jurci@stuba.sk, maria.hudakova@stuba.sk, martin.kusy@stuba.sk \\ ${ }^{3}$ Poznan University of Technology, Faculty of Mechanical Engineering, Poznan, Poland, EU, \\ dariusz.bartkowski@put.poznan.pl, damian.przestacki@put.poznan.pl \\ ${ }^{4}$ Czech Technical University in Prague, Faculty of Materials Engineering, Prague, Czech Republic, EU, \\ martin.kurik@fs.cvut.cz
}

https://doi.org/10.37904/metal.2020.3481

\begin{abstract}
The paper presents the study results of microstructure, phase composition, microhardness and wear resistance of Vanadis- 6 tool steel after diffusion boriding and laser processing. In this study the diode laser device was used. As a result of diffusion boriding the obtained surface layers were characterized by needlelike microstructure with good cohesion with the substrate but in the subsurface area delamination and porosity could be observed. Therefore the diffusion boronized layer was processed using laser heat treatment. As a result of influence of the laser beam, three zones were obtained. The remelted zone near the surface, next the heat affected zone and finally steel substrate were observed. The newly created microstructure in the remelted zone consisted of boron-martensite eutectic. Microhardness of boronized layer after laser processing in comparison to the one without laser processing was slightly lower and was approx. from $1300 \mathrm{HV} 0.1$ to 1100 HV0.1. It was found that additional advantage of laser processing of boronized layers was the presence of heat affected zone. This led to obtaining a mild microhardness gradient between the surface and the substrate. The boronized layer after laser processing was characterized by higher wear resistance in comparison to one not subjected to this kind of processing.
\end{abstract}

Keywords: Boronized layer, laser remelting, microstructure, microhardness, wear resistance

\section{INTRODUCTION}

The diffusion boronizing is a method of thermo-chemical treatment, which improves the properties of surface layers [1]. As a result of this process, boronized layer composed of needle-like microstructure of $\mathrm{FeB}$ and $\mathrm{Fe}_{2} \mathrm{~B}$ iron borides can be obtained. The FeB iron boride is characterized by a high microhardness approx. 1800 HV0,1, but in area of its occurrence brittleness may appear. As a result, it leads to microcracks or peeling of layer. Despite this defect, boronized layer has many advantages such as high hardness, good corrosion resistance in a number acid solutions as well as good wear resistance [1-5]. The brittleness in subsurface zone in boronized layer is the reason for the search for new methods of its modification. One such method is preparing a layer composed of only $\mathrm{Fe}_{2} \mathrm{~B}$ phase characterized by lower microhardness of about $1600-1400 \mathrm{HV}$. In recent times the boronized layers may be modified using diffusion [6], galvanic [7] and laser [8-10] processing. The last type of modification seems to be particularly interesting. Laser processing of surface 
layers produced on steel is rapid and precise. After laser modification the boronized layers obtain a new microstructure and properties. Undoubtedly, the laser processing has a positive influence on decreasing brittleness of layers. Additionally a reduction in microhardness gradient between surface and substrate can be obtained.

In this paper Vanadis-6 tool steel with boronized layer was laser processed using diode laser beam. The aim of this study was to determine the influence of laser processing parameters on the microstructure, microhardness and wear resistance of boronized layers.

\section{METHODOLOGY OF RESEARCH}

Experiments were carried out on Vanadis-6 powder metallurgical tool steel specimens and its chemical composition is shown in Table 1.

Table 1 Chemical composition of Vanadis-6 steel (\%wt.)

\begin{tabular}{|c|c|c|c|c|c|c|}
\hline $\mathbf{C}$ & $\mathbf{S i}$ & $\mathbf{M n}$ & $\mathbf{C r}$ & Mo & $\mathbf{V}$ & $\mathbf{F e}$ \\
\hline 2.09 & 0.98 & 0.38 & 6.64 & 1.48 & 5.45 & 82.98 \\
\hline
\end{tabular}

The production process of new surface layer is composed of several steps. In the first step, diffusion boronizing at temperature of $1030^{\circ} \mathrm{C}$ for 75 minutes was carried out using Durborid® mixture. Next austenitizing at $1025^{\circ} \mathrm{C}$, followed by quenching using a nitrogen gas and double tempering at $530^{\circ} \mathrm{C}$ for $2 \mathrm{~h}$ were conducted. Experimental setup for diffusion boronizing process is presented in Figure 1a. In the final step the diffusion boronized layers were laser processed. For laser processing the TRUDIODE 3006 diode laser with a nominal power of $3 \mathrm{~kW}$ was used. The laser device was integrated with the KUKA robotic arm. The scheme of the test stand as well as the model of laser processed surface layer are shown in Figure $\mathbf{1 b}$. The parameters of laser processing were as follows: laser beam power densities $(q): 38 \mathrm{~kW} / \mathrm{cm}^{2}, 64 \mathrm{~kW} / \mathrm{cm}^{2}, 127 \mathrm{~kW} / \mathrm{cm}^{2}$, scanning rate of laser beam $v=3 \mathrm{~m} / \mathrm{min}$ and laser tracks overlapping $-50 \%$.

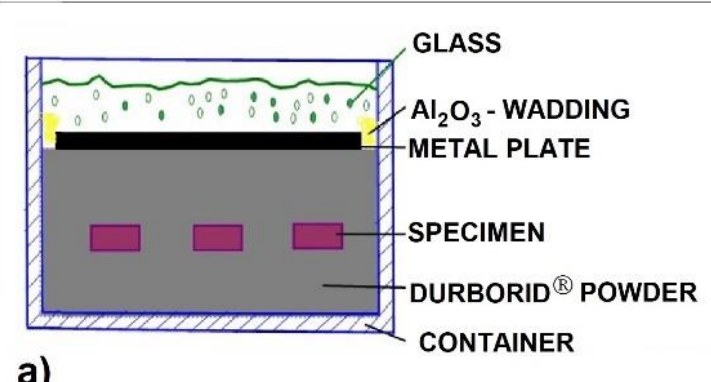

a)
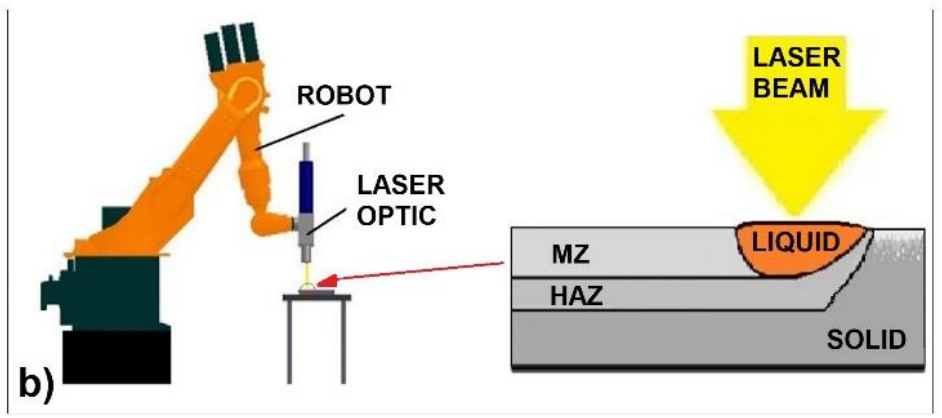

Figure 1 View of specimens preparation methodology for diffusion boronizing process (a) and scheme laser processing test stand with model of laser processed boronized surface layer (b)

Microstructure observations were carried out using Huvitz HRM-300 light microscope and JEOL JSM-7600F scanning electron microscope. The cross-sections of specimens were ground using abrasive papers, next were polished using $\mathrm{Al}_{2} \mathrm{O}_{3}$ and finally etched by $\mathrm{COR}$ reagent $\left(\mathrm{HCl}+\mathrm{CH}_{3} \mathrm{COOH}+\mathrm{C}_{6} \mathrm{H}_{3} \mathrm{~N}_{3} \mathrm{O}_{7}+\right.$ ethanol). The phase analysis of all tested surface layers was performed using EMPYREAN PANalytical X-Ray diffractometer with CoKa radiation. To determine microhardness profiles, an FM-810 Vickers microhardness tester from Future-Tech equipped with FT-Zero automatic indentation measuring software was used. Indentation load of $100 \mathrm{G}$ (HV0.1) and the loading time of 15 seconds were applied in these studies. Tribological properties of boronized layers before and after laser processing were measured using the CSM pin-on-disc tribometer at ambient temperature. Balls of $6 \mathrm{~mm}$ diameter, made from sintered alumina were used for these tests. During wear tests no external lubricant was applied, and the load was $5 \mathrm{~N}$. The total sliding distance was $100 \mathrm{~m}$. The 
wear rate was calculated from the width of the track by using the formula according to ASTM G 99-95a standard. In the wear volume calculations, the radius of pin point and depth of penetration were taken into account, whereas in the sliding distance calculation, the wear circle radius was included.

\section{RESULTS AND DISCUSSION}

Microstructure of boronized layer on Vandadis-6 steel after conventional heat treatment is shown in Figure 2. Diffusion boronized layer has a characteristic needle-like microstructure, which is continuous, uniform and oriented perpendicularly to the surface with good cohesion with the substrate. But in the subsurface zone of layer a little delamination and porosity could be observed. In microstructure of Vanadis- 6 steel substrate, the chromium and vanadium carbides which are evenly distributed in martensite are visible. Smaller, vanadium carbides and larger chromium carbides are detected [8]. The thickness of needle-like microstructure of boronized layer was about $60 \mu \mathrm{m}$. It must be stated that that thickness of boronized layer produced on Vanadis6 steel is less than the thickness of layer produced on low carbon steels. Also the shape of needles is different, without sharp ends of needles as on low carbon steel. This phenomenon is related to a decreased boron diffusion rate during boronizing process as a result of the high carbon content.

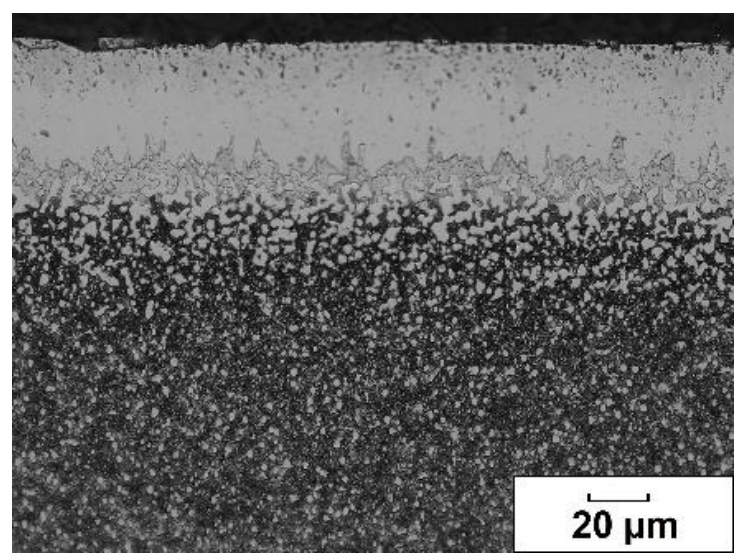

Figure 2 Microstructure of Vanadis-6 steel after diffusion boriding and conventional heat treatment

In Figures 3a-3f the microstructures of Vanadis-6 steel with boronized layer after laser processsing are presented. In the microstructure two characteristic zones can be distinguished: remelted zone (MZ) and heat affected zone (HAZ). The remelted zone is composed of boron-martensite eutectic, while in the heat affected zone, fine carbides in the background of fine-grained martensite were visible. Below these two zones the microstructure of substrate, which does not exhibit changes compared with specimens before laser processing is visible. As a result of laser processing, the microstructure of boronized layer is changed which may affect the increase of ductility of newly formed layer. Figures $\mathbf{3 b}, \mathbf{3} \mathbf{d}, \mathbf{3} \mathbf{f}$ show the magnification of the central area of the remelted zone from Figures $3 a, 3 c$ and $3 e$ respectively. The influence of laser beam power density at constant scanning laser beam rate on laser track dimensions and microstructure in remelted zone was analyzed. It could be concluded that when laser beam scanning rate was constant but laser beam power density was variable, then increasing laser beam power induces creation of larger laser tracks (Figures 3a, 3c, 3e). Laser processing contributes to intensive mixing of the preformed boronized layer with the substrate material. But, using too low power laser beam results in complete remelting of boronized layer on the border of laser tracks. This is because the remelted zone has a depth of approx. $30 \mu \mathrm{m}$ whereas the boronized layer has approx. $50 \mu \mathrm{m}$ (Figure $3 \mathbf{e}$ ). Figure $3 \mathbf{b}$ presents the microstructure of the central part the remelted zone from Figure $3 \mathbf{a}$ at high magnification. Boron eutectic along with alloy martensite are visible. Figure $\mathbf{3 d}$ presents the microstructure of the remelted zone from Figure $3 \mathbf{c}$, where boron eutectic with martensite can be seen, but with a higher proportion of eutectic. The highest content of boron eutectic with martensite can be seen in Figure 3f. Therefore, depending on the parameters used, the remelted zone with hypoeutectic structure ( $\alpha-$ 
phase + eutectic) in Figure $\mathbf{3 b}$, hypereutectic microstructure (eutectic + iron boride and carbides) in Figure $\mathbf{3 f}$ and purely eutectic microstructure in Figure $\mathbf{3 d}$ may be identified. Boron-martensite eutectic in remelted zone can take different shapes i.e. branched, round, prismatic, or angular which was also confirmed by Safonov [10]. In microstructure of remelted zone various shades can be seen after etching. It is related to the changes of chemical composition in microstructure, due to fluctuation of melted material. Clear transition area between remelted zone, a heat affected zone and the substrate is also visible. The boronized layers before and after laser processing were analyzed using XRD method, and the results showed that the remelted region or layer was composed of iron borides and martensite. In the diffusion boronized layer, $\mathrm{FeB}$ and $\mathrm{Fe}_{2} \mathrm{~B}$ phases are present which was also confirmed in papers [5, 8]. Phase composition results are shown in Figure 4. After laser processing of boronized layers, equilibrium iron boride phases $\mathrm{FeB}$ and $\mathrm{Fe}_{2} \mathrm{~B}$, non-equilibrium and probably meta-stable iron-carbon-boride phase $\left(\mathrm{B}_{0.7} \mathrm{Fe}_{3} \mathrm{C}_{0.3}\right)$ as well as $\mathrm{Fea}$ iron phase were identified. Similar phases were presented by Safonov in paper [10] where the steel substrate was covered with a paste of amorphous boron, and next laser processing was conducted.
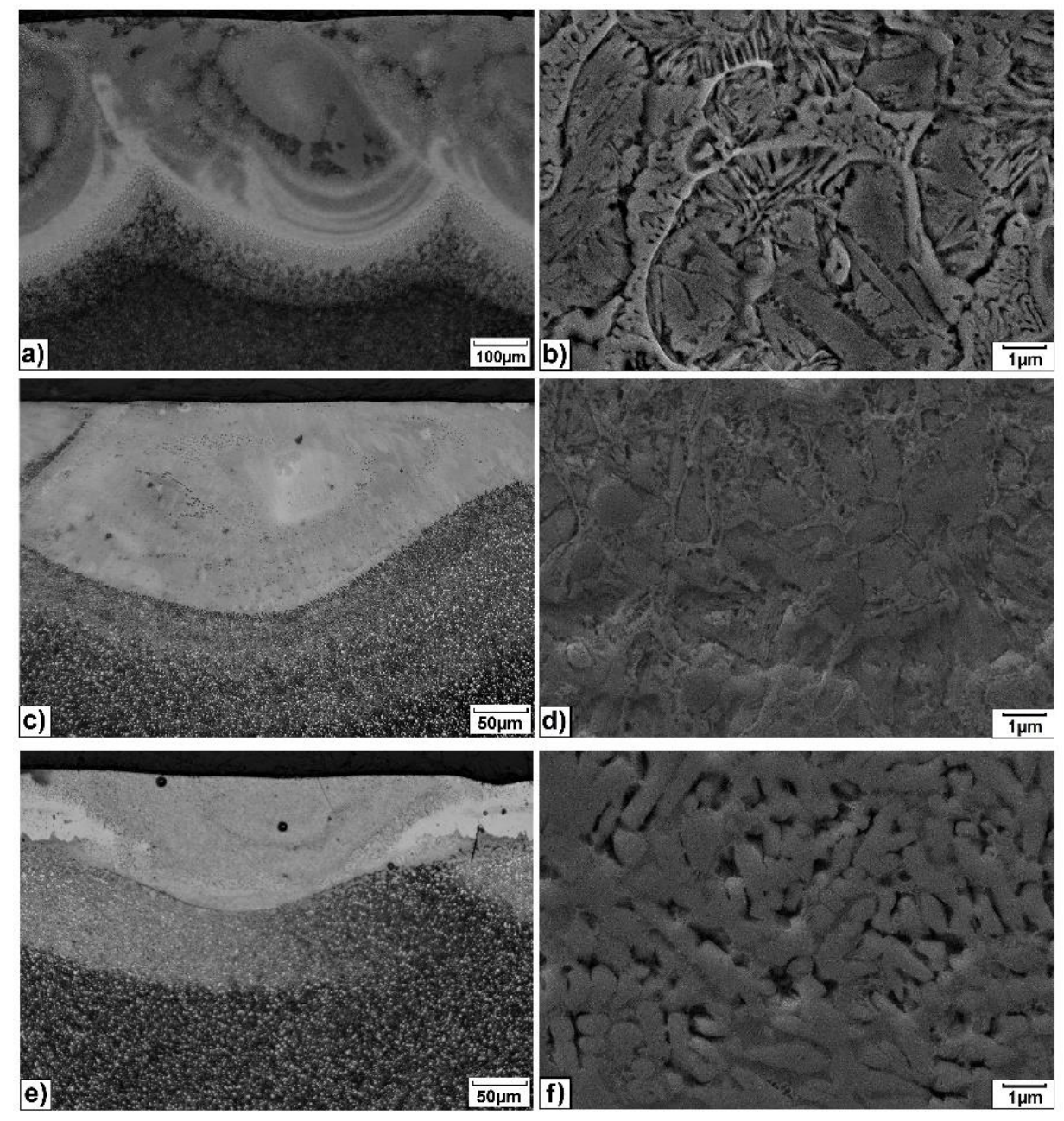

Figure 3 Microstructure of boronized layers after laser processing; laser tracks left column, magnified area of laser track - right column; $q=127 \mathrm{~kW} / \mathrm{cm}^{2}(\mathrm{a}, \mathrm{b}), q=64 \mathrm{~kW} / \mathrm{cm}^{2}(\mathrm{c}, \mathrm{d}), q=38 \mathrm{~kW} / \mathrm{cm}^{2}(\mathrm{e}, \mathrm{f})$

Microhardness of boronized layer produced on VANADIS 6 steel was between 1800 and $1400 \mathrm{HV}$ and is presented in Figure 5a. Figures $\mathbf{5 b} \mathbf{b} \mathbf{5} \mathbf{d}$ show the microhardness of borided layers after laser processing, and the depths of remelted zone and HAZ are marked on the graphs. It may be noted that the laser processing parameters have an influence on microstructure and consequently on the microhardness of laser tracks. Figure $\mathbf{5 b}$ shows the microhardness of boronized layer after laser processing using the highest laser beam 
power density (its microstructure is presented in Figure 3a). The microhardness was approx. $1100 \mathrm{HV}$. However, decreased laser beam power density affects the increase in microhardness in the remelted zone to about $1300 \mathrm{HV}$. In all the analyzed specimens, microhardness profiles gradually decrease from remelted zone through heat affected zone to the substrate. Microhardness in HAZ oscillates within the range of 900-800 HV, and then decreases to the value of approx. $700 \mathrm{HV}$ in the substrate. It can be seen that the microstructure of the formed eutectic has an influence on microhardness. Therefore a specimen with hypereutectic microstructure had higher microhardness (Figure $\mathbf{3 f}$ and Figure 5d). It can be found that due to laser processing the microhardness of new layers was lower than in diffusion boronized layers but much thicker (even 2 to 6 times). This depends on laser processing parameters.

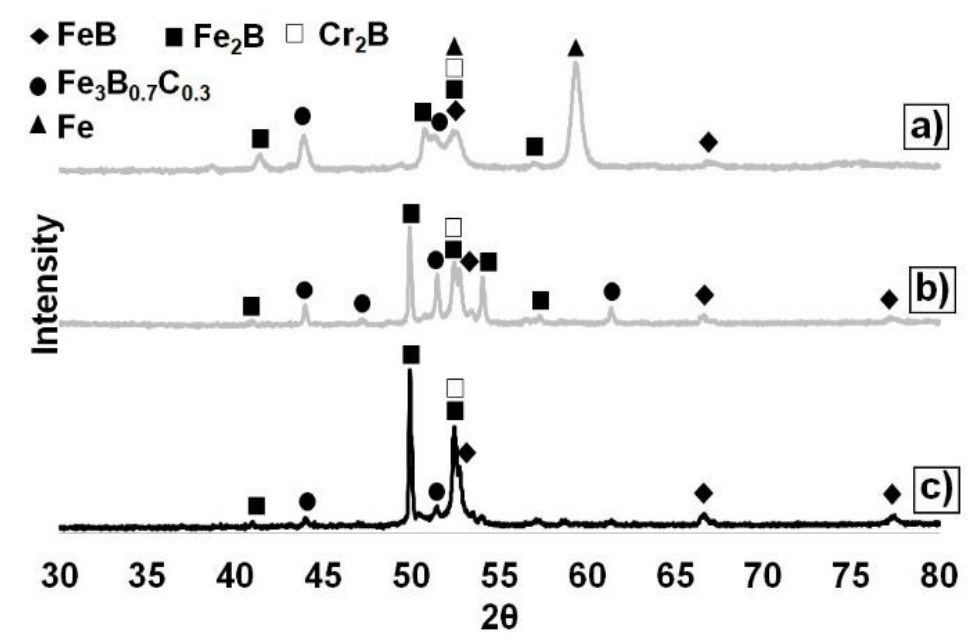

Figure $4 \mathrm{XRD}$ spectrum of boronized layers after laser processing; $q=127 \mathrm{~kW} / \mathrm{cm}^{2}(\mathrm{a}), q=64 \mathrm{~kW} / \mathrm{cm}^{2}(\mathrm{~b}), q$ $=38 \mathrm{~kW} / \mathrm{cm}^{2}(\mathrm{c})$
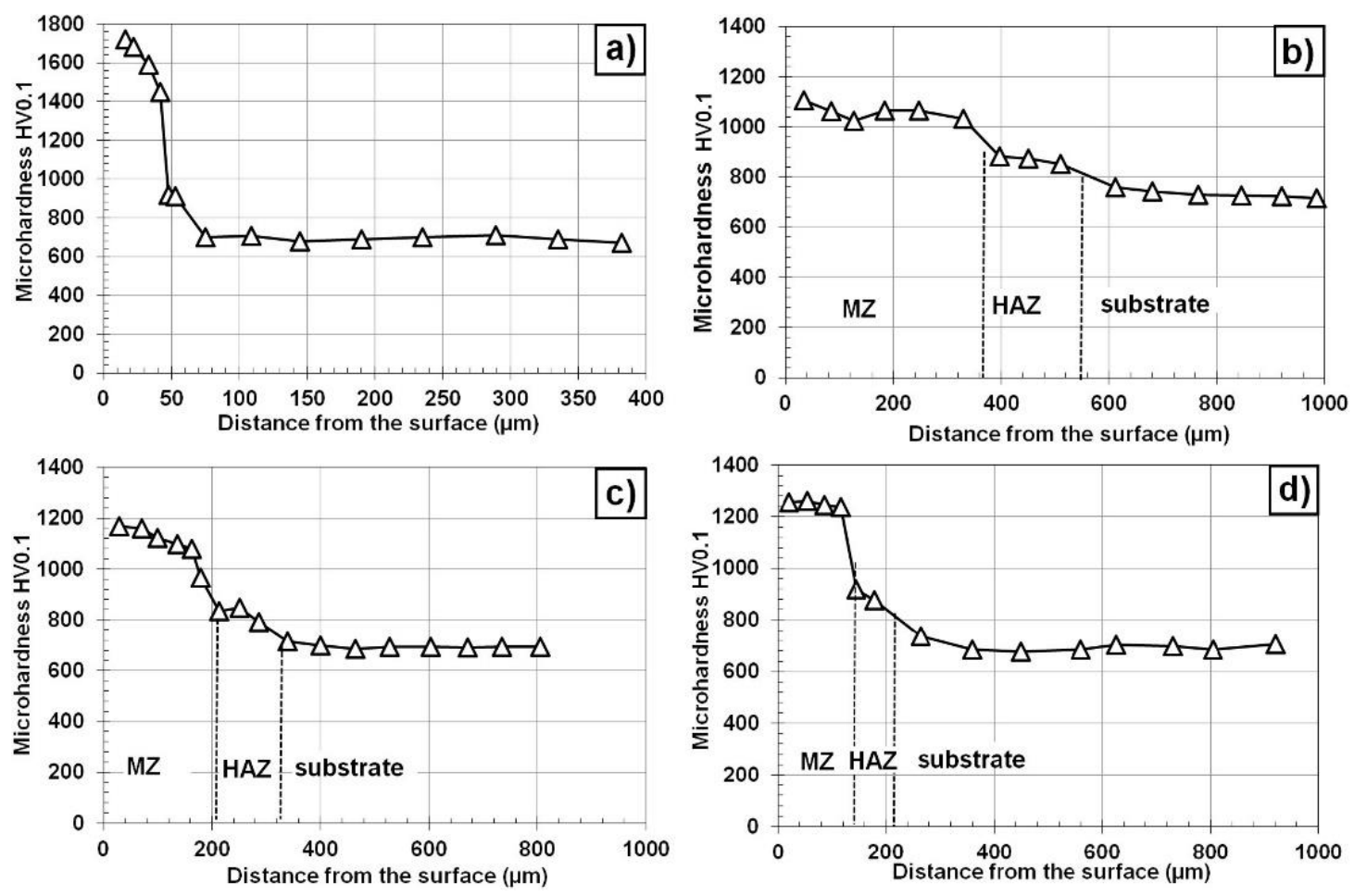

Figure 5 Microhardness profiles of Vanadis- 6 steel with boronized layers: after diffusion process (a) and after laser processing using: $q=127 \mathrm{~kW} / \mathrm{cm}^{2}(\mathrm{~b}), q=64 \mathrm{~kW} / \mathrm{cm}^{2}(\mathrm{c}), q=38 \mathrm{~kW} / \mathrm{cm}^{2}$ (d) 
The results of wear resistance tests of boronized layer before and after laser processing conducted using pinon-disc method are presented in Table 2. Boronized layer with the highest microhardness and characterized by hypereutectic microstructure was selected for testing. The received friction coefficient measured for diffusion boronized layer was slightly lower than what was achieved in the case of laser remelted boronized layer.

Table 2 Wear resistance results obtained using pin-on-disc method

\begin{tabular}{|l|c|c|c|}
\hline Specimens & $\begin{array}{c}\text { Values of friction } \\
\text { coefficient }\end{array}$ & $\begin{array}{c}\text { Widths of wear tracks } \\
(\mathbf{m m})\end{array}$ & $\begin{array}{c}\text { Wear rate } \\
\left(\mathbf{m}^{2} / \mathbf{N}\right)\end{array}$ \\
\hline boronized layer & 0.562 & 0.176 & $5.90 \cdot 10^{-10}$ \\
\hline boronized layer after laser processing & 0.626 & 0.202 & $5.58 \cdot 10^{-10}$ \\
\hline
\end{tabular}

From the measurements of the width of wear tracks it is shown that the wear rate of laser processed specimen is slightly better than for diffusion boronized layer. Slightly lower wear rate is related to thicker layer after laser processing which generally had a lower microhardness than that diffusion boronized layer.

\section{CONCLUSION}

The conclusions are as follows:

- Laser processing of boronized layer reduces microhardness gradient on cross-section from the surface to the substrate in comparison to diffusion boronized layer. It is associated with the presence of heat affected zone.

- $\quad$ Laser processing contributes to reducing the microhardness from approx. from $1700 \mathrm{HV} 0,1$ to 1400 $\mathrm{HV} 0,1$ (for diffusion boronized layer) to approx. from $1300 \mathrm{HV0}, 1$ to $1100 \mathrm{HV0,1}$ (for laser processed boronized layer).

- After laser processing, in microstructure of boronized layer, $\mathrm{Fe}_{2} \mathrm{~B}, \mathrm{Fe}_{3} \mathrm{~B}_{0.7} \mathrm{C}_{0.3}$ and $\mathrm{Fea}$ phases were detected.

- Wear resistance tests using pin-on-disc method did not show significant improvement of the wear resistance of laser processed boronized layer in comparison to the diffusion boronized layer.

\section{ACKNOWLEDGEMENTS}

Presented work has been financed by the Ministry of Science \& Higher Education in Poland in 2020 year under Project No 0513/SBAD/4607. Additionally, part this work was supported by the MEYS of the Czech Republic program NPU1, project No. L01207.

\section{REFERENCES}

[1] KRUKOVICH, M.G., PRUSAKOV, B.A., SIZOV, I.G. Plasticity of Boronized Layers. Springer Series in Materials Science. Springer International Publishing, 2016. ISBN 978-3-319-40012-9 (eBook)

[2] MUHAMMAD, W. Boriding of high carbon high chromium cold work tool steel. IOP Conference Series: Materials Science and Engineering. 2014, vol. 60, pp. 1-6.

[3] CALIK, A., SIMSEK, M., KARAKAS, M.S., UCAR, N. Effect of boronizing on microhardness and wear resistance of steel AISI 1050 and chilled cast iron. Metal Science and Heat Treatment. 2014, vol. 56, pp. 89 - 92.

[4] KULKA, M. Current Trends in Boriding: Techniques. Springer International Publishing, 2019. Online ISBN 978-3030-06782-3

[5] JURČI, P., HUDÁKOVÁ, M. Diffusion boronizing of H11 hot work tool steel. J. Mater. Eng. Perform. 2011, vol. 20, pp. 1180-1187. 
[6] BALANDIN, Yu.A. Termochemical treatment in fluidized bed. Surface hardening of die steel by diffusion boronizing, borocopperizing and borochromizing in fluidized bed. Metal Science and Heat Treatment. 2005, vol. 47, pp. 103-106.

[7] WIERZCHOŃ, T., BIELIŃSKI, P., SIKORSKI K. Formation and properties of multicomponent and composite borided layers on steel. Surface and Coatings Technology. 1995, vol. 73, pp. 121-124.

[8] BARTKOWSKA, A., SWADŹBA, R., POPŁAWSKI, M., BARTKOWSKI, D. Microstructure, microhardness, phase analysis and chemical composition of laser remelted FeB-Fe2B surface layers produced on Vanadis- 6 steel. Optics \& Laser Technology. 2016, vol. 86, pp. 115-125.

[9] GOPALAKRISHNAN, P., SHANKAR, P., SUBBA RAO, R.V., SUNDAR, M., RAMAKRISHNAN, S.S. Laser surface modification of Low Carbon Borided Steels. Scripta Materialia. 2001, vol.44, pp. 707-712.

[10] SAFONOV, A. N. Special features of boronizing iron and steel using a continuous-wave $\mathrm{CO}_{2}$ laser. Metal Science and Heat Treatment. 1998, vol. 40, no.1 - 2, pp. 6-10. 